
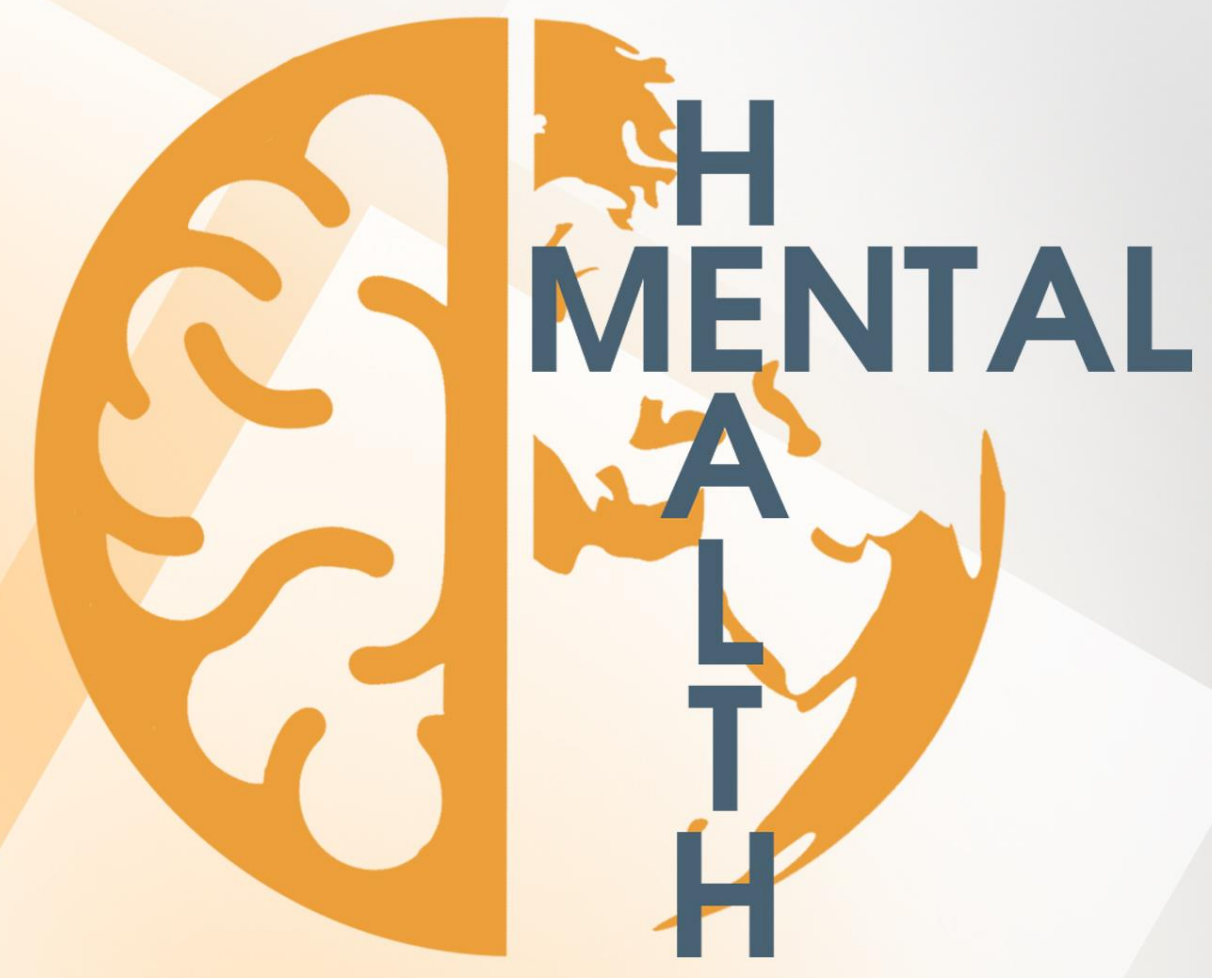

\title{
Global challenges
}

MHGC Journal

Rome 2019 


\section{Publication frequency}

\section{1-2 issue/year}

\section{Founders}

The MHGC Journal was originally founded by NDSAN Network (MFC Coordinator of the NDSAN) (Italy)

\section{Issue status}

National/International

\section{Issue languages}

English

\section{Media environment}

\section{International}

\section{Target audience}

Scientists/researchers (medical, social, educational fields and etc.), mental health $(\mathrm{MH})$ practitioners, policy-makers, researchers, lawyers.

Mental Health: Global Challenges Journal is an open access peer-reviewed journal, whose main aim is to promote dialogue and debate on topics such as Mental Health, Mental Health Care Systems and etc.

Mental Health: Global Challenges Journal is a journal dedicated to international studies on MHC systems in the context of global social challenges, Mental health and migration, Mental health in times of military conflicts, Mental health and community, Specific issues of MHC, Higher Education and MHC, Interdisciplinary and transdisciplinary approaches in $\mathrm{MHC}$, and related topics, therefore we will encourage those papers which focus on the specific particularities from these topics, and /or authors coming from these areas.

The journal considers with a special attention the manuscripts which can be of interest for policy makers and/or practitioners.

The journal accepts manuscripts such as theoretical articles, research articles, case studies, reviews, abstracts

\section{Field of study and special focus}

Mental Health, Medicine, Psychology, Social Sciences, Education, Economics, Law, Inter- and Transdisciplinary studies 
Editor-in-chief: Dr. Viktor Vus, Associate Professor

Vice Editor: Dr. Maureen P. Flaherty, Assistant Professor (CA)

\section{Editorial Board:}

Dr. Ioanna V. Papathanasiou, Assistant Professor, (GR)

Dr. Elena Syurina, Assistant Professor, (NL)

Dr. Daniela Dumitru, Associate Professor (RO)

Dr. Evangelos C. Fradelos, Associate Professor (GR)

Dr. Valentina Vitale, $\mathrm{PhD}$ (IT)

Mag. Galina Itskovich, LCSW (USA)

\section{Editorial Team:}

Dr. Tatyana Danylova, Associate Professor (UA)

UDK 159.922.27:316.33(811.111)

DOI: http://doi.org/10.32437/mhgcj.v1i1

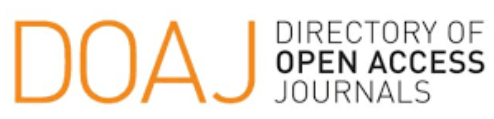

: CiteFactor
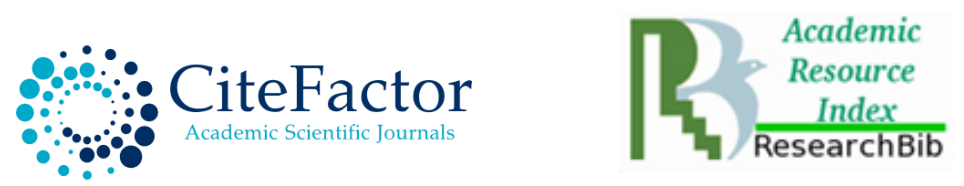

(1) Scilit

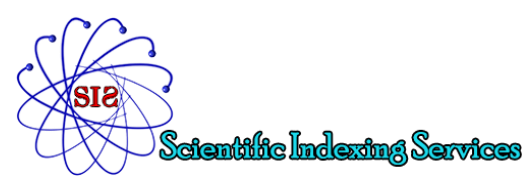




\section{CONTENT}

Giuseppina Ancona, Eleonora Fulco, Simone Marchese

Alina Costin, Liliana Renate Bran

Fradelos C. Evangelos, Eirini Kapsiocha, Anna Neroliatsou, Sofia Kastanidou, Konstantinos

Tsaras, Dimitrios Papagiannis, Ioanna V. Papathanasiou

Anna Kohut, O. Potapov, I. Frankova, M. Bobryk, J. Komisarenko, O. Chaban

Mganga Bwire

Olena Kostyuk, Olena Boychuk

Pádraig Ó Féich

Konstantinos Tsaras, Evangelia Christopoulou, Maria Malliarou, Evangelos

C. Fradelos, Stiliani

Kotrotsiou, Ioanna V. Papathanasiou
Community mental health: health budgets in a multifactorial context use and how do they understand preventing it?

Assessment of psychological distress in university students: A Quantitative study

Consequence of Psychosocial Factors on the Adherence to Treatment of the Patients with Type 2 Diabetes Mellitus

Increasing acess to healthcare among persons with mental health disorders in Zanzibar

Psychological condition of grieving family members and their resocialization

Towards a Recovery Orientated Mental Health

Service: Findings from a National Consultation with Mental Health Service Users in Ireland

Impact of job burnout on mental health among social workers in public and private sector in Greece 


\section{COMMUNITY MENTAL HEALTH: HEALTH BUDGETS IN A MULTIFACTORIAL CONTEXT Giuseppina Ancona ${ }^{1}$, Eleonora Fulco ${ }^{2}$, Simone Marchese ${ }^{3}$}

Department of Mental Health, Provincial Health Company of Agrigento (ASP), Agrigento, Italy

Introduction In the last three years the Department of Mental Health of the ASP (Provincial Health Company) Agrigento (Italy) has become the protagonist of an attempt to change the cultural reality of mental health in its own territory, to ready local communities to overcome the prejudices linked to the stigma connected to psychiatric pathology through the implementation of an experimental project funded by the Sicily Region, the PON (National Operational Plan) 19.2. At the same time, the Department of Mental Health of the Provincial Health Authority (ASP) has experimented with the introduction of flexibility in care pathways for serious patients so as to pursue a model of integrated intervention combining the efforts public health, private social, citizens (training / work, residential care) in which public health continues to respect the responsibility and ownership of the service but is enriched with new human resources to promote patient citizenship itineraries.

All this is in order to prevent mental health problems, stimulate the inclusion and active participation of those suffering from mental health problems recognizing the experience and skills of patients and caregivers as an essential basis for the planning and development of mental health services ${ }^{1}$.

The goal of the project was to reduce the isolation of psychiatric patients by adopting new methods that determined an economic saving and a higher quality in therapeutic results: tools within the Health Budget ${ }^{2}$. This is a qualitative and quantitative definition of tools of the economic, professional and human resources necessary to trigger a process aimed at restoring the centrality of the person with mental illnesses within their care system.

The catalyst for the process of change was a "multidisciplinary staff" (group of carers) composed of psychiatrists, psychologists, social workers, professional nurses operating in a specific area who, through a continuous process of training and co-visioning ${ }^{3}$ have acquired new knowledge, shared experiences, fears, difficulties and innovative choices.

Another important element in this challenge is the integration between patient and local community. Until a few years ago, interventions in mental health were aimed at passive subjects (patients) who were the recipients of therapeutic interventions designed by health care professionals and delivered to outpatient clinics.In the last twenty years we have worked to apply the provisions of the various Objective - Mental Health Protection Projects ${ }^{4}$. The Sicily Region has today adopted a model based on a greater awareness of the patient and on the

\footnotetext{
${ }^{1}$ World Health Organization, European Ministerial Conference on Mental Health, Helsinki, Finland, January 12th15th 2005, Declaration on Mental Health for Europe

${ }^{2}$ Righetti A., "Health budgets and community welfare", Laterza, Bari 2013

${ }^{3}$ The co-vision device is a clinical discussion group composed of peers in which there is no supervisor present

${ }^{4}$ Official Gazzette, Approval of Objective Project "Mental Health Protection" 1994-1996, n. 93 of 22/04/1994 and Official Gazzette, Approval of Objective Project “Mental Health Protection" 1998-2000 n. 274 of

22.11.1999 
possibility that he or she has an active role in decisions about their therapeutic project (recovery).

The new clinical model of recovery is "a profoundly and truly personal process of changing one's values, feelings, goals, capacities and roles. It is a way of living one's life with satisfaction, hope and initiative, despite the suffering and limitations caused by the disease. It involves the recovery not only of a condition of greater well-being, but rather of a new sense of one's existence, which can be made to evolve beyond the catastrophic effects of mental illness " (William Anthony, 1993) ${ }^{5}$. According to community mental health and recovery models ${ }^{6}$, the patient, where they have the potential, must acquire a degree of selfdetermination that will allow them to make realistic choices about their health and take advantage of the treatment opportunities offered to them.

\section{The "National Operational Plan (PON) 19.2"}

This work refers to some actions contained in the P.O.N. - line 19.2, including the Health Budget. The goal of the article is to show and monitor, through actionresearch, the evolution of the clinical process in some patients with severe psychiatric diagnosis, over a period of eighteen months. All this is in order to highlight the greater therapeutic and economic efficacy of community care, compared to the "classic" one based mainly on a welfare model. The hypothesis of intervention is based on the use of the group and the Local Community ${ }^{7}$ as tools of change, (Staff Group, patient group, team group, family group). It is up to the multidisciplinary staff of the services to legitimize the patient in their role as an active element within the care process, so as to give them a social role allowing them to reactivate the momentarily lost potentialities and to learn new ones.

The main working tool was the use of the P.T.I. (Individualized Therapeutic Project) ${ }^{8}$. This is a document constructed by the clinicians working with the patient, but which must be discussed with the patient and their family. In the document are reported: the psychopathological diagnosis and assessment; the personal and social functioning of the individual, the objectives to be achieved, the tools and methods of intervention, the case manager, the necessary resources, the implementation times, the process and methods for monitoring and verifying results. Within the P.T.I. the psychopathological evaluation takes place using the Brief Psychiatric Rating Scale (BPRS) ${ }^{9}$ while the part related to personal and social evaluation contains the questions of the Camberwell Assessment of Need (CAN) ${ }^{10}$, an interview to identify care needs. A term of six monthis is scheduled to verify the results.

\footnotetext{
5 Anthony W., Recovery from Mental Illness: The Guiding Vision of the Mental Health Service System in the 1990s, http://citeseerx.ist.psu.edu/viewdoc/download?doi=10.1.1.690.1878\&rep=rep1\&type=pdf

6 Ibidem and also Anthony, W. et al. . "Psychiatric Rehabilitation." Boston, MA: Center for Psychiatric Rehabilitation, Sargent College of Health and Rehabilitation Sciences. Boston, MA: Boston University. 2002

${ }^{7}$ Barone R., Bruschetta S., D’Alema M. L'inclusione sociale e lavorativa in salute mentale. Buone pratiche, ricerca empirica ed esperienze innovative promosse dalla rete AIRSaM, Franco Angeli, Milano 2013

${ }^{8}$ GURS (Sicily Region Official Gazette), Strategic Plan for Mental Health, June 15th 2012, pag. 37

${ }^{9}$ Overall J.E. , Gorham D.R., The Brief Psychiatric Rating Scale, in Psycological reports, 1962, 10, 799-812, Southern Universities Press 1962

${ }^{10}$ Phelan, M., Slade, M., Thornicrotf, G., Dunn, G., Hollway, F., Wykes, T., Strathdee, G., Loftus, L., McCrone, P. \& Hayward, P. (1995). The Camberwell Assessment of Need: the validity and reliability of an instrument to assess the needs of people with severe mental illness. British Journal of Psychiatry 167, 589-595
} 
The executive project, "Regional and Intercompany Program for implementation of actions to protect mental health in adulthood programmed by PANSM for the Priority Area of Needs: Serious Persistent and Complex Disorders" was coordinated by a project manager and a management team and had the scope of intervention the strengthening the LEA (Essential Levels of Assistance) to protect mental health in adulthood, within the rehabilitation therapeutic programs provided for by the Strategic Mental Health Plan of the Sicily Region. The LEAs in this area do not refer to single services but to protocols for taking charge, taking into account the particular complexity and multi-factorial nature of major psychiatric disorders.

The project involved the activation of 6 Multidisciplinary Staff (one for each territorial area of the ASP of Agrigento except for one) composed of at least 3 operators who had a total of:

- 16 patients, in possession of P.T.I., trained to become social facilitators for mental health with Health Care Workers Budget (forms of temporary work of a socialrehabilitation nature).

- 7 patients with P.T.I. included in the Health Budget "Temporary Family Foster Care" (Patients entrusted to families other than their own).

\section{Health budgets: Social Facilitation and Foster Care}

Social facilitators ${ }^{11}$ are people who have gone through a mental illness and who have reached awareness, empowerment and the ability to live with their own symptoms within their care pathway. Through adequate training and continuous updating, they have the possibility of transforming their own experience and their path of "disease and healing" into a resource for the help and and support of other users. The facilitator plays an important mediation role in communicating with the health team. The facilitator accompanies the user in the social network of the services the user needs, supports the user in training and / or work choices, helps plan the management of free time, supports the individual during the entire process of social reintegration, even supporting him/her in daily activities (shopping, cooking, keeping the house clean and safe, ...).

Temporary alternative care refers to the inclusion of a patient in an "other" family unit to live a life, although in a temporary form, characterized by ties and relationships similar to those that occur in a family. The most important element is that ordinary citizens take charge of the psychiatric pathology together with the clinical staff, contributing to the spread of a community mental health. At the same time the patient plays an active role choosing their course of care; he or she is considered to be equal among the various other figures involved in the project.

\section{The Action - Research}

The study was carried out in the form of research-intervention, in a circular process between knowledge and transformation of reality, whereby the theory directs the action addressed to change and the effects reorganize the knowledge learned. Lewin

\footnotetext{
${ }^{11}$ Barone R., Duca R., Leonardi R, Auteri M.Y., Pezzano R. FACILITATORE SOCIALE: il supporto fra pari in salute mentale, Nuova rassegna di studi psichiatrici, Rivista on line di psichiatria Volume 17, 3 settembre 2018 http://www.nuovarassegnastudipsichiatrici.it/index.php/numeri-precedenti/volume-17/facilitatore-sociale-ilsupporto-fra-pari-in-salute-mentale 
defines intervention research as "Studying things by changing them (intervention) and seeing their effects (research)" ${ }^{12}$.

The objective is therefore to study the phenomena while changing them. The experimental nature of the interventions underlying the implementation of individualized projects has determined the need to monitor and evaluate, during the same 18 month period, two different clinical processes of P.T.I. pertaining to two different project actions: the Social Facilitator Users Project and the Temporary Family Foster Care Project. The two projects will be described below separately.

As for the first one, the Social Facilitators in Mental Health Project, the multidisciplinary clinical staff adhered to the idea that selected patients, adequately trained and supported by the services they belong to, could assist operators in managing one or more patients with some deficits in personal and social functioning, becoming a resource for services and local communities. Sixteen patients were selected for the project: 14 were trained and 13 of them benefited from work grants lasting 6 months. The 13 patients who undertook the path of the Job Grants belonged to the Care Paths with the diagnosis of: Schizophrenic Disorder (4), Bipolar Disorder (4), Severe Personality Disorder (1) and Schizoaffective Disorder (1). From the analysis of P.T.I. it emerged that all the selected patients were characterized by a stable clinical picture with good conditions of compensation, good relational and social performances and a stable therapeutic compliance. All the phases of the project were periodically monitored. In the phase preceding the training and during the training there were monthly meetings with the multidisciplinary staff and with the facilitator users; after the training there were regular meetings with the health services to plan the start of the actions. During the realization of the work grants there were meetings of the co-vision group composed of user facilitators and two operators of the Department of Mental Health. At the same time, monitoring was carried out at the mental health services to define, in agreement with the facilitators, the projects started and monitor the clinical progress of the patients who were followed by the facilitators.

The projects assigned took into account the possibilities offered by the services, the users' predispositions and the clinical evaluations made by the service operators. In most cases the facilitators were assigned a user already in charge of the DSM. Among whose objectives present in their P.T.I. there was improvement in the management of daily activities, knowing how to use the resources offered by the territory and the community, and improvment in the level of personal and social autonomy. In other cases the facilitators were employed within the services to organize workshops aimed at other users, starting from the skills possessed by the patient facilitators.

To assess the outcome of the clinical processes that were performed during the 18 months of observation, a questionnaire was prepared with a re-test 4 months after the test, aimed at patients with work grants as well as a questionnaire to be given to the operators of the services.

From the quantitative and qualitative analysis of questionnaires addressed to patients, a vision of themselves and of the work they carry out emerges, characterized by the development of a greater capacity of empowerment linked, on

${ }^{12}$ Lewin K. (1948), The child in the social environment, La Nuova Italia, Florence, 1967 
the one hand, to the acquisition of greater skills related to the work of facilitator, to a greater self-awareness. These elements make patients more capable of coming into contact with themselves, with regards to their own abilities and potential, as well as their own limits.

These elements contribute to a greater perceived self-efficacy that makes them even safer in relationships with each other. Above all from the relationship with the operators and with their own mental health service they acquired the security that makes them feel "protected" even in their work as facilitators. These factors, of course, do not totally shield people from the difficulties that any job implies but which, at present, they are able to cope. The re-test questionnaire also highlighted the reduction of the idealized expectations that emerged from the beginning of the project and which were constantly worked on in the moments of co-vision.

The second project, a Temporary alternative Care Project, involved 7 DSM users. The 7 patients who undertook the project path presented the following diagnoses: Bipolar disorder, Paranoid schizophrenia (3), Schizophrenic psychosis, Schizoaffective disorder, Bipolar disorder, mixed episode, severe, with psychotic behavior.

The patients involved in this project had a clinical picture characterized by greater severity in the impairment of interpersonal skills and autonomous management of daily activities. Then, the selection of patients took place using the following criteria: poor social functioning, the presence of difficulties in adapting to changes, poor self-care, poor autonomy in daily management, low self-esteem. All these aspects that, in the past, would have induced medical personnel to institutionalize patients, with an economic burden on the community and isolating them from it.

The evaluation of clinical processes took place through a questionnaire, addressed to multidisciplinary staff, with 7 closed-ended questions and 3 openended questions. In the former, an attempt was made to assess the quality of the relationship between foster family and the patient entrusted, the relationship between both with the service and possible improvements for patients. In the latter, respondents were asked to indicate the critical points of the project and the areas in which the improvements of the patients occurred.

The answers to the questionnaire highlighted the importance of the foster family in increasing patients' sense of confidence, improving self-esteem, restoring relational skills and improving self-care, also thanks to an understanding of the nature of their own role of support and accompaniment. The services played an important role, representing a catalyst and a point of reference for a foster family and the patient entrusted. In a field test six months later, patients showed greater stability in the clinical picture and an evolution in personal and social functioning: greater personal care, trust in the operators, improvement of daily performance with more care in the environments of life. The foster families represented a real transformative flywheel and placed the patient-citizen within the community. Patients experienced healthy relationships and the foster families have played a mediating role between the patient and the local community.

\section{Conclusions}

In conclusion, it can be stated that the Community P.T.I., undertaken by multidisciplinary staff, patients and citizens, is not intended as a linear process but 
as a complex path that involves small steps, failures and successes, respecting individual differences, of the specific life stories, of the diagnostic picture, of the personal and social functioning level of the patient and of the degree of inclusion. In most cases, during the observation period, the patients involved in the research showed a greater capacity to manage their moments of difficulty and crisis. They were better able to give themselves the right time to "get back on track" and start again. Participants gradually acquired a new role that no longer coincides exclusively with that of "patient", but has also diversified according to the expansion of their own interests and life goals. The growth in empowerment level has also translated into a greater spirit of initiative both in personal daily contexts and in the relationship with mental health services operators and with the community itself. All this does not coincide with the patient's clinical recovery but certainly with the acquisition of "a new sense of one's existence, which can be made to evolve beyond the catastrophic effects of mental illness" ${ }^{13}$ and it is "the being part" of a social context that demonstrates how the full involvement of the community represents the multifactorial response to mental distress ${ }^{14}$. The project, in fact, led the operators to think of themselves in a totally different way than in the past; it forced them to reconsider roles (their own, that of patients and that of family members), to rethink the organization of services and to reformulate the therapeuticrehabilitative offers ${ }^{15}$. This has cracked the certainties, albeit crystallized, that characterize routine work to embrace, often and willingly, doubt, uncertainty, fear of making mistakes, and frustration. As it is easy to imagine all this has represented a great effort that is still underway because those who really decide to question themselves are "condemned" to do so always, otherwise sooner or later they fall back into the crystallization of certainties that, although reassuring, flatten thought. Kahn ${ }^{16} 17$ pointed out that the perception of meaning by employees towards the task performed is an important driver for engagement. According to the author, in fact, the perception of meaning can be achieved through the assignment of challenging and varied tasks.

Having first crossed this "minefield" has allowed operators to more effectively transmit to patients the message proposed by the concept of recovery: the activation of a process aimed at building a way of life based on a sense of selfefficacy, free from the control of health institutions and tending to the exercise of one's life potential, which however is not free from hitches, errors, falls, etc., like any human event. But the staff members have also shown that if the services no longer have to have a rigid control over the patients, they can however continue to represent a professional and human support in the realization of the patients' life project.

The inclusion of patients in the world of work and in hetero-family contexts, in collaboration with the Local Authority and the third sector who shared training programs, P.T.I.s and operating practices with mental health services, contributed

\footnotetext{
${ }^{13}$ Anthony, W. A., Cohen, M., Farkas, M, \& Gagne, C. (2002). Psychiatric rehabilitation, 2nd edition. Boston, MA: Boston University, Center for Psychiatric Rehabilitation

${ }^{14}$ Barone R., Bruschetta S., Frasca A. La ricerca sui gruppi comunitari in salute mentale. La valutazione clinica delle reti sociali e la psicoterapia di comunità orientata alla recovery, Franco Angeli, Milano 2014

${ }^{15}$ Barone R., Bellia V., Bruschetta S, Psicoterapia di comunità. Clinica della partecipazione e politiche di salute mentale, Franco Angeli, Milano 2010

${ }^{16}$ Kahn WA. Psychological conditions of personal engagement and disengagement at work. Acad Manage J 1990; 33: 692-724

${ }^{17}$ Kahn WA. To be full there: psychological presence at work. Hum Relat 1990; 45: 321-49 
in fact to the different perception that society has of a psychiatric patient: not just a patient to be assisted but a citizen with needs and resources. "The answer to a disability is not a bed, it is rehabilitation" "18. "Rehabilitation does not mean having a protected structure but involves reconstructing the contractual nature of the people so that they can re-enter the circuit of sociality" 19.

The launch of the actions envisaged by the project, whose financing is limited in time, requires an even wider cultural change to ensure that these devices become an integral part of the rehabilitation tools also at the level of an enlarged community. In this sense the work that involves the awareness of Local Authorities and operators of the Third Sector is still ongoing and will involve the writers and all the operators of the ASP of Agrigento involved in the project.

\section{Bibliography}

Anthony W., Recovery from Mental Illness: The Guiding Vision of the Mental Health Service System in the 1990s, http://citeseerx.ist.psu.edu/viewdoc/download?doi=10.1.1.690.1878\&rep=r ep1\&type=pdf

Anthony, W. et al. . "Psychiatric Rehabilitation." Boston, MA: Center for Psychiatric Rehabilitation, Sargent College of Health and Rehabilitation Sciences. Boston, MA: Boston University. 2002

Anthony, W. A., Cohen, M., Farkas, M, \& Gagne, C. (2002). Psychiatric rehabilitation, 2nd edition. Boston, MA: Boston University, Center for Psychiatric Rehabilitation

Barone R., Bellia V., Bruschetta S, Psicoterapia di comunità. Clinica della partecipazione e politiche di salute mentale, Franco Angeli, Milano 2010

Barone R., Bruschetta S. , D'Alema M. L'inclusione sociale e lavorativa in salute mentale. Buone pratiche, ricerca empirica ed esperienze innovative promosse dalla rete AIRSaM, Franco Angeli, Milano 2013

Barone R., Bruschetta S., Frasca A. La ricerca sui gruppi comunitari in salute mentale. La valutazione clinica delle reti sociali e la psicoterapia di comunità orientata alla recovery, Franco Angeli, Milano 2014

Barone R., Duca R., Leonardi R, Auteri M.Y., Pezzano R. FACILITATORE SOCIALE: il supporto fra pari in salute mentale, Nuova rassegna di studi psichiatrici, Rivista on line di psichiatria Volume 17, 3 settembre 2018

http://www.nuovarassegnastudipsichiatrici.it/index.php/numeriprecedenti/volume-17/facilitatore-sociale-il-supporto-fra-pari-in-salutementale

GURS (Sicily Region Official Gazette), Strategic Plan for Mental Health, June 15th 2012, pag. 37

Kahn WA. Psychological conditions of personal engagement and disengagement at work. Acad Manage J 1990; 33: 692-724

\footnotetext{
${ }_{18}$ Saraceno B., Towards an inclusive and participatory Mental Health, Report Open lecture, 15/05/2019, http://www.sportellotiascolto.it/salute-mentale-inclusiva-e-partecipata-report/

${ }^{19}$ Ibidem 
Kahn WA. To be full there: psychological presence at work. Hum Relat 1990; 45: 321-49

Lewin K. (1948), The child in the social environment, La Nuova Italia, Florence, 1967

Official Gazzette, n. 93 of 22/04/1994

Official Gazzette, n. 274 of 22/11/1999

Overall J.E. , Gorham D.R., The Brief Psychiatric Rating Scale, in Psycological reports, 1962, 10, 799-812, Southern Universities Press 1962

Phelan, M., Slade, M., Thornicrotf, G., Dunn, G., Hollway, F., Wykes, T., Strathdee, G., Loftus, L., McCrone, P. \& Hayward, P. (1995). The Camberwell Assessment of Need: the validity and reliability of an instrument to assess the needs of people with severe mental illness. British Journal of Psychiatry 167, 589-595

Righetti A., "Health budgets and community welfare", Laterza, Bari 2013

Saraceno B., Towards an inclusive and participatory Mental Health, Report Open lecture, 15/05/2019, http://www.sportellotiascolto.it/salute-mentaleinclusiva-e-partecipata-report/

World Health Organization, European Ministerial Conference on Mental Health, Helsinki, Finland, January 12th-15th 2005, Declaration on Mental Health for Europe.

Keywords mental health, community, health 


\title{
WHAT DO TEENAGERS PARENTS KNOW ABOUT DRUG USE AND HOW DO THEY UNDERSTAND PREVENTING IT?
}

\author{
Alina Costin, Liliana Renate Bran
}

„Aurel Vlaicu” University of Arad, Romania

\begin{abstract}
Introduction On one hand, drug use has become an extremely welcomed subject because it „needs to be”, and because it has to be treated seriously; on the other hand, it is addressed to with great ignorance among all the actors directly involved in handling this phenomenon. The problem of drug use, with all the dimensions of it, must take care of this behavior and it can be classified as mental health problems, which will have multiple consequences for their care in the health plan. Literature has already become a classic, such as Learning Theories (Bandura, 1986, Skinnere, Thorndike, etc.), Family-Based Theories and Systemic Approach (Waldrom, 1998), and more recent works by Stephen J. Bahr, John P. Hoffmann, Xiaoyan Yang, stresses the role of the family in building child protection factors for substance use. The purpose of this research is to investigate the parents of the high school students in Arad Municipality regarding the information they have about drugs, their perception related to their child's relationship with drugs and how they "treat" this topic.

Design The qualitative information we want to obtain has imposed a specific design for qualitative research. The study is descriptive and has a practical orientation- it was carried out between June and September 2019.

Methodology - We have created 8 focus groups with parents of high school students with different demographic characteristics (level of education, religion, provenance, family status) and we have made 3 profound interviews for each category of people we have selected. This paper presents the preliminary qualitative results of a study that is still in progress. The focus groups carried out indicates that the vast majority of parents treat this topic of consumption superficially. Their parenting principle is based on building a strong, positive and open relationship, but the child is a fundamental premise in preventing any deviat behavior. \{ \{ ce este inainte de paranteza este modificat de mine din propozitia asta - but they have as a parenting principle that to build a strong positive, open and dialogue relationship, but the child, which is a fundamental premise in preventing any deviant behavior. The originality of this study and why it was realised is due to the lack of information upon this subject, at least in this city, Arad, and the main limitations consit in the imposibility of generating the conclusions regarding the whole population concerned.
\end{abstract}

Keywords: drug use, preventing, family, protection factors 


\title{
Assessment of psychological distress in university students: A Quantitative study
}

\author{
Fradelos C. Evangelos ${ }^{1}$, Eirini Kapsiocha ${ }^{1}$, Anna Neroliatsou ${ }^{2}$, Sofia Kastanidou ${ }^{1}$, \\ Konstantinos Tsaras ${ }^{1}$, Dimitrios Papagiannis ${ }^{1}$, Ioanna V. Papathanasiou ${ }^{1}$ \\ ${ }^{1}$ General Department, University of Thessaly, Larisa, Greece \\ ${ }^{2}$ University Hospital of Larisa, Larisa, Greece
}

\begin{abstract}
.
Introduction: Psychological health is the expression of harmonic expression of human's personality and is often disrupted by multiple factors. Especially, during academic years human has to confront various stressful situations that endanger his Psychological health.
\end{abstract}

Aim: This study aims to assess psychological distress in university students and to examine possible factors that are associated with it.

Material and Methods: A cross sectional study was conducted in which 206 university students were participated. Data were collected by the Hospital Anxiety and Depression Scale, HADS and a sheet contain information regarding demographic, social and academic background special design for the purpose of the study. Spss v. 21 was used for analyzing data and the signicant level was set in $\mathrm{p} \leq 0,05$.

Results: From the total of 206 students 76,2\% were women $(n=157)$ and 23,8\% were men with a mean age $30.1 \pm 7.15$. Anxiety symptoms were negative associated with cohabitation and marital status ( $\mathrm{p}=.019$ and $\mathrm{p}=.001$ respectively). While place of residence was also negative associated $(\mathrm{p}=.000)$. While monthly income and duration of were associated with the experience of anxiety symptoms. One the other hand depression was associated with sex $(\mathrm{p}=.004)$ place of residence and origins of students $(\mathrm{p}=.038$ and $\mathrm{p}=.058$ respectively). Finally, the number of uncompleted courses and sexual preferences were associated with depression to $(\mathrm{p}=.009)$.

Conclusions: Within the context of student life that is characterized by anxiety, crises of interpersonal relationships and uncertainty maintaining student's mental health and wellbeing must be a top propriety among university services.

Keywords. Anxiety, depression, distress, University students 


\title{
Multidisciplinary Intention: Revealing The Consequence of Psychosocial Factors on the Adherence to Treatment of the Patients with Type 2 Diabetes Mellitus
}

\author{
Anna Kohut1, O. Potapov ${ }^{2}$, I. Frankova ${ }^{3}$, M. Bobryk ${ }^{3}$, J. Komisarenko ${ }^{3}$, O. Chaban ${ }^{3}$ \\ 1 Communal Institution of Kyiv Regional Council "Regional Psychiatric and Narcological \\ Medical Association", Glevakha, Ukraine \\ 2 Center for Innovative Medical Technologies of the National Academy of Sciences of \\ Ukraine, Kyiv, Ukraine \\ 3 Bogomolets National Medical University, Kyiv, Ukraine
}

Background: Diabetes Mellitus type 2 (T2DM) has been becoming a global world health problem affecting countries with different income level (Mogre, Johnson, Tzelepis, Shaw, \& Paul, 2017). The low level of compliance and the increased level of the diabetes distress has been closely associated with destitute glycemic control. Some diabetes-specific psychological variables may be important for psychological status of patients and glycemic control to the achievement of individual glycemic targets (Indelicato et al., 2017). Therefore, alexithymia - psychological clinical characteristic of the reduced emotional component that could have been associated with the metabolic syndrome in patients with type 2 diabetes, for example (Lemche, Chaban, \& Lemche, 2014). It is important to consider the clinical evaluation of mental aspects in patients with T2DM, however, in order to preventing potentially unfavorable self-care behavior leading to complications of this disease, including a decrease in the quality of life level (Conti et al., 2017). Patient's level of the quality of life is the one of main important components of treatment adherence and clinical decision making for improving the effectiveness of therapy (Chaban, Khaustova, \& Bezsheiko, n.d.). The low level of medication compliance and quality of life could have been addicted in consequence to non-adherence and respectively inefficiency of therapy of these patients. Therefore, multidisciplinary connection involving mental health care specialists can potentially improve treatment effectiveness (Kogut at al., 2018).

Purpose: Aim of the study was-comprehensive assessment of psychological status and quality of life of the patients with T2DM to explore the relationships with their commitment to treatment depending by the level of compliance for medication.

Method: Study population $(\mathrm{n}=40)$ consists of the patients with T2DM (male -32 , $5 \%$, female $-67,5 \%$ ), married $-60 \%$, widow $-25 \%$, single $-15 \%$; had higher completed education $-60 \%$, had the different level of obesity $-50 \%$ of patients. Study data have been collected with the demographic data (including: age, BMI, the level of arterial pressure, blood glucose and glycated hemoglobin (HbA1c) laboratory results); Chaban Quality of Life Scale (CQLS), Medication Compliance Scale (MCS), Holmes and Rahe Stress Scale (HRSS), Dysfunctional attitudes Scale (DAS), Toronto Alexithymia Scale (TAS-20) and the Depression, Anxiety and Stress Scale (DASS-21)). Glycemic control was based on HbA1c results. The 
statistics analysis has been performed by using descriptive statistics and Pearson's correlation with SPSS Statistics 23.0.

Results: Statistically significant difference has been found between the groups of the patients with low, middle and high level of their compliance to therapy according to MCS results. Strong relationships have been found between the numeral scores by MCS with the DAS ( $\mathrm{p}<0,0001 ; \mathrm{r}=-0,57)$, TAS-20 ( $\mathrm{p}=0,006 ; \mathrm{r}=$ $-0,42)$, HRSS $(\mathrm{p}=0,001 ; \mathrm{r}=-0,524)$ and DASS-21 (depression $(\mathrm{p}<0,0001 ; \mathrm{r}=-$ $0,703)$, anxiety $(\mathrm{p}=0,001 ; \mathrm{r}=-0,498)$, stress $(\mathrm{p}<0,0001 ; \mathrm{r}=-0,62))$ results significant bilateral indirect correlation and direct by CQLS results of scores on level $(p=0,22 ; r=0,361)$. Therefore, statistical difference have been detected between the results of: glucose level $(\mathrm{p}=0,032 ; \mathrm{r}=-0,349)$; depending by the belonging to the group of different results between level of cognitive distortions (DAS) $(\mathrm{p}=0,001 ; \mathrm{r}=-0,508)$, alexythimia (TAS-20) $(\mathrm{p}=0,001 ; \mathrm{r}=-0,498)$, stress $(\mathrm{p}<0,0001 ; \mathrm{r}=-0,67)$, depression $(\mathrm{p}<0,0001 ; \mathrm{r}=-0,71)$, anxiety $(\mathrm{p}=0,007 ; \mathrm{r}=-0,418)$ (DASS-21), stress resistance (HRSS) $(\mathrm{p}=0,008 ; \mathrm{r}=-0,416)$ and quality of life $(\mathrm{p}=0,44 ; \mathrm{r}=0,32)$.

Based on the results of research - there has been found the strong relationship between the results of MCS with low level of compliance and high level by the scores of psychometric scales, as evidenced, that these patients would be have low rates of treatment effectiveness in the future.

Conclusions: The possible psychosocial factors affecting the level of compliance and psychological status indicators in patients with Diabetes Mellitus type 2, which have been determined based on the results of research, such as the level of: quality of life, stress resistance, alexithymia, cognitive distortions, anxiety, depression and distress of these patients. Therefore, patients with a low level of commitment to treatment have had a higher risk of treatment failure and needed qualified help from specialists on various failures to ensure the multidisciplinary approach to the treatment of patients with Diabetes Mellitus type 2.

Originality: The concept of "adherence to treatment" is so comprehensive, in contrast to the concept of "compliance" or "commitment" to treatment, in a medication aspect.

Limitations of the study: The low sample of T2DM patients, that has been planning to correction in further researches.

Strengths of the study: The urgency of this problem in the vast field of research and development in both medical and social sciences. The multidisciplinary approach would have been promising and innovative direction for the future.

\section{References}

Chaban, O., Khaustova, O., \& Bezsheiko, V. (n.d.). Reliability and validity of Chaban Quality of Life Scale. Retrieved from 
https://www.ecnp.eu/presentationpdfs/70/P.2.h.301.pdf

Conti, C., Di Francesco, G., Fontanella, L., Carrozzino, D., Patierno, C., Vitacolonna, E., \& Fulcheri, M. (2017). Negative Affectivity Predicts Lower Quality of Life and Metabolic Control in Type 2 Diabetes Patients: A Structural Equation Modeling Approach. Front Psychol. 24;8:831. doi: 10.3389/fpsyg.2017.00831

Mogre, V., Johnson, N., Tzelepis, F., Shaw, J., \& Paul, C. (2017). Adherence to self-care behaviours and associated barriers in type 2 diabetes patients of low-and middleincome countries: a systematic review protocol. Syst Rev. 2017 Feb 27;6(1):39. doi: 10.1186/s13643-017-0436-4.

Indelicato, L., Dauriz, M., Santi, L., Bonora, F., Negri, C., Cacciatori, V., Targher, G., Trento, M., \& Bonora, E. (2017). Psychological distress, self-efficacy and glycemic control in type 2 diabetes. Metab Cardiovasc Dis. 2017 Apr;27(4):300-306. doi: 10.1016/j.numecd.2017.01.006. Epub 2017 Jan 31.

Lemche, A., Chaban, O., \& Lemche, E. (2014). Alexithymia as a risk factor for type 2 diabetes mellitus in the metabolic syndrome: a cross-sectional study. Psychiatry Res. 215(2):438-43. doi: 10.1016/j.psychres.2013.12.004

Kogut, A., Bobryk, M., Potapov, O., Frankova, I., Komisarenko, J., Khaustova, O., \& Chaban, O. (2018). Multidisciplinary Approach to Research of the Adherence to Treatment Phenomenon in Patients with Diabetes Mellitus. Mental Health: Global Challenges Journal, Rome (pp. 40-41). DOI: http://doi.org/10.32437/MHGCJ-2018

Keywords: diabetes, health, health care, medical, medical research, medical science, medicine, mental health, mental stress, psychology, quality of life, social well-being 


\title{
CASE STUDY
}

\section{INCREASING ACESS TO HEALTHCARE AMONG PERSONS WITH MENTAL HEALTH DISORDERS IN ZANZIBAR}

\author{
Mganga Bwire
}

Zanzibar Psychiatric Association, Kenya

\begin{abstract}
The abstract is a case study highlighting initiatives designed by the Zanzibar Psychiatric Association (ZPA) to serve persons with mental disorders (MHDs) confined indoors. The purpose of the program was to increase access to healthcare among confined MHDs. This was achieved through conducting outreach programs aimed at community awareness creation on MHDs, providing first aids to the patients and referring to the MHDs designed hospitals. Moreover, the program focused on advocating for increased local health budget prioritizing on mental health. A total of 63 patients reached and provided with first aids and referred to the hospital, meanwhile 200 people form the community were educated on MHDs. Limited funding to operationalize interventions fueled by increased demands are some of the key challenges. We urge like-minded partners to join hands in our initiatives in providing experts, technical advises and other resources so that we can scale-up interventions in Zanzibar.
\end{abstract}

Keywords. Mental health, healthcare, Zanzibar, psychiatry.

\section{Context/background}

Zanzibar is an Island that is part of the United Republic of Tanzania. It is an archipelago composed of two islands, Unguja and Pemba. Like its Counterpart, mainland Tanzania, Zanzibar is significantly affected by Non-Communicable Diseases (NCDs), one of them being mental health disorders (MHDs). Generally MHDs among young people in Tanzania is attributable to a number of factors including increased demands for means of survival, use of psycho-active drugs (drugs addiction), persistence of HIV/AIDS epidemic and other socio-economic challenges like abject poverty (Mahenge, Stöckl, Likindikoki, Kaaya, \& Mbwambo, 2015). Common forms of MHDs in Zanzibar includes schizophrenia, depressions, epilepsy and Neuro-cognitive disorders (NCDs). Data collected at Kidongo-chekundu Mental Hospital (KCMH) in Zanzibar in 2018 showed 10, 645 total outpatients. According WHO national survey in 2011, Zanzibar had a MHDs prevalence of $6.8 \%$ (men $4.7 \%$ and women $8.8 \%$ ) (Mental Health Strategic Plan2014).

One of the critical challenges facing MHDs in Zanzibar is limited access to healthcare. The common practice is that patients are confined indoors while fixed in shackles. This practice is attributable due to the fact that vast number of people believe that MHDs cannot be cured with mere biomedical means. In other hand, those who believe in biomedical treatment have limited access to healthcare specialised for MHDs (physical barriers and other indirect costs), and lack of psychiatrists and neurologists. Zanzibar has only one public health facility that provides services for MHDs with only two specialists. Therefore, these barriers compel them to resort to using traditional headers and sheikh's prayers and concoction called "kombe". In-house confinement has critical detrimental impacts to the patient including deteriorating patients. Furthermore, confinement violates the rights to inherent dignity, freedom from torture, right to liberty and other 
degrading treatment enshrined in the Universal Declaration of Human rights (1948), The Banjui Charter (1981), the Constitution of the United Republic of Tanzania (1977) and the Constitution of the Revolutionary Government of Zanzibar (2010).

\section{About the program}

Zanzibar Psychiatric Association (ZPA) is a Non-governmental organization located in Unguja-Zanzibar-Tanzania. Its mission is to improve the quality of life for those with mental illness, including substance use disorders and those affected by epilepsy. Some of our interventions include facilitating access to mental health services, education, treatment, medication, and support programs.

ZPA collected and documented information regarding MHDs in Zanzibar through households' surveys; referrals from community members and local government authorities (sheias). ZPA draw a conclusion that there is a significant number of persons suffering from MHDs confided indoors hence resorted to intervene. ZPA designed a voluntary program to reach these vulnerable persons. Through this program, ZPA conducted outreach programs with its voluntary health workers (VHWs). The program involved the following interventions: 1. Identifying patients in the communities through house-holds visits and referrals 2. Sensitizing parents, guardians and relatives of the patient on MHDs especially on its possibility of cure 3 providing first aid to the patients using Mental health GAP Action Program (MHGAP). 4. Referring the patient to the hospital after seeking their consent via counselling. Apart from direct service to the targeted beneficiaries, ZPA has been conducting strategic policy advocacy programs aimed at increasing budget allocation to health sector with a focus to mentor health. Experience reveals that NCDs including mental health have not been given priorities it disserves.

\section{Purpose of the program}

The purpose is to contribute to increasing access to healthcare among MHDs in Zanzibar.

Objectives: 1. Increasing awareness on mental health disorders among community members 2. Advocating for increased local budget on health targeting MHDs

\section{Results}

Increasing Access to Healthcare Among Persons with Mental Health Disability Through Home Visits program has significantly contributed in improving health outcomes of persons with mental disability in Zanzibar. Some of critical outcomes include: 1. Visiting a total of 200 householders and providing mental health education. 2. Improving health outcomes of 63 patients and referring them to the health facilities 3 . Holding a total of 3 engagement sessions aimed at increasing local budget on health sector and documented commitment of policy and decision makers.

\section{Resources}

ZPA has been using membership contributions from its members which is in a tune of Tshs 6,000 per year that equals USD 2.60 per person and other humanitarian aids from stakeholders to operationalize its programs. For example, ZPA has been receiving free mental health drugs from partners. To make programs sustainable, the management has been charging a fee of Tshs 2,000 (that is USD 0.90) per visit. However, these contributions are not sufficing the operational needs.

\section{Achievements}

Amplifying visibility of mental health problem within the ambit of the policy and 
decision makers and community at large is worthy mentioning. ZPA has contributed substantially in raising awareness to the government and community on the magnitude of the problem of mental health in Zanzibar. Additionally, a proportion of the community members understanding the significance of health facilities on healthcare of persons with mental disability has increased.

\section{Challenges}

1.Limited funding to finance programs. People work on voluntary basis which sometimes impair their motivations

2.Client's over-expectations. Some clients expect ZPA to provide more than it can offer

3. Limited facilities to accommodate patients. In Zanzibar there is only one hospital designated for mental disorders (Kidongo-chekundu Mental Hospital-KCMH) with only 2 specialists. Therefore, it can admit only 120 patients.

4. Stigma and discrimination perpetrated by some parents, guardians, relatives, community members and some health service providers (HSPs) against people with mental disorders which act as a barrier towards accessing healthcare.

5. Lack of modern equipment to diagnose epilepsy in Zanzibar. One partner offered a free machine (EEG machine) but we need to have some funds for hosting installers and trainers and purchasing medications.

\section{Key learning points}

1. Zanzibar is one of the areas with high prevalence $(6.8 \%)$ of mental health disorders but astonishingly have only 2 psychiatrists which is against WHO doctorpopulation ratio

2. No direct local budgetary allocation allotted for mentor health disorders

3. Health Insurance companies are reluctant to insure persons with mental disorders

4. Customs, traditions and practices influence perceive misconceptions that mental disorders are attributed to sorcerers therefore a patient should be referred to traditional healers and sheikhs (98\% of Zanzibarians are Muslims)

\section{Future plans}

1. Scaling-up outreach programs to reach more patients especially in rural settings and link them to health facilities

2. Conducting a national program focusing on providing a comprehensive and accurate information on mentor health in Zanzibar

3. Advocating for inclusiveness of persons with mentor retardations in decision making pertaining to: family decision making (inheritance, child bearing etc.), voting, voluntary treatment, employment etc.

Keywords. Mental health, healthcare, Zanzibar, psychiatry 


\title{
PSYCHOLOGICAL CONDITION OF GRIEVING FAMILY MEMBERS AND THEIR RESOCIALIZATION
}

\author{
Olena Kostyuk ${ }^{1}$, Olena Boychuk ${ }^{2}$ \\ ${ }^{1}$ P.L Shupyk National Medical Academy of Postgraduate Education, National University of \\ "Kyiv Mohyla Academy", Kyiv, Ukraine \\ ${ }^{2}$ National University of "Kyiv Mohyla Academy", Vadym Hetman Kyiv National Economic \\ University, Kyiv, Ukraine
}

\begin{abstract}
Introduction. Personal development in competitive and adverse conditions gives us plenty of examples that show negative behavior and incapability of making peace between nations. The situation in the world today confirms the previous statement, Ukraine suffers more than many other countries because of the powerful neighbor from the East who forces our country to accept his conditions. The war in Eastern Ukraine is the consequence of this irrational and atavistic tendency. We are the victims of the aggravation between two dialectic processes of social activism: disconnection (destructive situations, ATO, loss of a family member, family break up, heightened level of aggression in the community) connection (constructive and creative appearances, adaptation in conditions of forced immigration, posttraumatic growth, resocialization after overcoming trauma, tendency for reconciliation, personal growth in a new profession).

This is the reality that requires psychological science and practice to find quick and accurate answers because the goal is to save people's mental health in military and mobilization conditions.
\end{abstract}

Purpose. The main goal of the research is to generalize the information about psychological features of the people who have experienced loss. Also to spot the stages of women's post-loss resocialization and factors that have a positive impact on that resocialization.

Methodology. The authors of this paper made research on the psychological features of the people who have experienced loss due to military situation in the East of Ukraine and who need psychotherapy to help the process of resocialization. The facts stated in the paper that helped to analyze the situation were received during work in the period of 2015-2018 at the center of psycho-social rehabilitation at National University of "Kyiv Mohyla Academy". 5370 people have addressed to the center to get help during this period. 1414 of them have gotten individual consultations, 3953 have participated in group therapies.

Keywords. military losses, mental effects, types of lesions, gender characteristics, means of assistance and re-socialization

Introduction. Viktor Muzhenko, the Chief of the General Staff and the commanding officer of the Armed Forces of Ukraine has reported that the estimated death toll in the East of Ukraine 2014-2017 includes 4,000 members of Ukrainian forces which means that the amount of families who lost their relative is practically same. We can assume that about 12-18 thousand people had to deal with the problem of losing a family member because of Anti-Terroristic Operation Zone. For each one of those people, it was a period when their usual norms and 
everyday lifestyle was either ruined or changed completely because of the tragic events that happened in their families.

To our point of view, the actuality of grief and loss problem is underrated. Considering our experience, we can state that widows and mothers after loss deserve the same attention as ATO zone veterans or their family members. Today's problem is that due to the heightened interest for ATO zone veterans, and their rehabilitation those who have lost their beloved ones during the war are not interested in coming to professional psychologists and psychotherapists themselves. Because this problem is not well represented in scientific researches, we have practically no information about the flow of the grieving process and its dynamic. We also do not know the amount of people who have pathological kind of grief and the amount of people whose resocialization is productive with or without psychotherapy.

The actuality of the research made on secondary socialization becomes even more important considering the fact that this process can have many complications or sometimes even stops for those who have faced loss. To be stuck in grief and total lack of re-socialization leads to:

1. Deprivation in all the lifestyle conditions, psycho-physiological, social, economic, cognitive-information, professional, etc.

2. The primitivization and deformation of the lifestyle strategy, self-doubt and upbringing destructive scenario into life.

3. Immune system disorders and lack of resilience to life challenges.

4. Constricted social circle, sometimes total estrangement.

Talking about widows who have children, all the problems also transfer to them. Social deprivation of parents who lost their childlchildren spreads itself on the whole family system. The importance of creating special conditions that can help working with those who are traumatized by loss is confirmed by the fact that the closest environment of the patient gets affected too. Honoring the lives of the dead and supporting their families can also be a factor that helps to form a stronger patriotic spirit of the nation and its younger generation.

Purpose. The main purpose of this paper is to describe the psychological features of those who had to deal with loss, to define the stages of resocialization for those women who have lost their beloved ones and the conditions that help to overcome loss.

Design\Methodology. Work in the center of psychological rehabilitation of National University of «Kyiv-Mohyla Academy» during 2015-2018 has become the main material for this article. 5370 people came to the center to get help during this time, 1417 of them have gotten individual consultation, 3953 took part in a group training.

Chart 1.

\begin{tabular}{|l|r|r|r|r|r|}
\hline & $\mathbf{2 0 1 5}$ & $\mathbf{2 0 1 6}$ & $\mathbf{2 0 1 7}$ & $\mathbf{2 0 1 8}$ & total \\
\hline total & $\mathbf{7 1 3}$ & $\mathbf{9 4 2}$ & $\mathbf{1 6 1 3}$ & $\mathbf{2 1 0 2}$ & $\mathbf{5 3 7 0}$ \\
\hline individual & 60 & 383 & 417 & 557 & 1417 \\
\hline group & 653 & 559 & 1196 & 1545 & 3953 \\
\hline
\end{tabular}

Among all the clients of our center women prevail man in 3.5 times, in fact, there are no men among those who came. We can suppose that this fact is related to gender stereotypes. Only $0.6 \%$ of all clients address for help due to "loss reason", women make $0.77 \%$ of them.

Chart 2.

\begin{tabular}{|l|l|l|l|l|l|l|}
\hline & 2015 & 2016 & 2017 & 2018 & total & $\begin{array}{l}\text { \% of people who } \\
\text { addressed for help }\end{array}$ \\
\hline
\end{tabular}




\begin{tabular}{|l|l|l|l|l|l|l|} 
total & 713 & 942 & 1613 & 2102 & 5370 & $0,6 \%$ \\
\hline Men & 154 & 243 & 349 & 448 & 1194 & $0 \%$ \\
\hline Women & 559 & 699 & 1264 & 1654 & 4176 & $0,77 \%$ \\
\hline
\end{tabular}

Such insignificant number of addresses with a problem of loss can be connected to several reasons:

- lack of attraction to psychotherapy of the mentioned type of people.

1. The absence of information about the effectiveness of psychotherapy or people's disbelief in it.

2. Fear of letting other people into one's private life.

In the past three years, we have created 3 special groups of psychotherapy for those people who have faced loss. Those groups included 28 women, each group had about 6-8 meetings. One third of those who have gone through individual and group therapy also took part in stabilizing group events of our center, like "Magic of breathing", "Soma-relax", "Right hemisphere drawing" or "Mandala therapy", patients visited our playback theater and also came for a consult because of problems with children.

24 more women who had to deal with grief received individual help due to the CETA program (Common Elements Treatment Approach).

We used two well-tested forms of psychotherapy, a short-term with 5 sessions, middle term with 8-12 sessions. CETA uses cognitive behavioral therapy methods and is lead by the JHU Applied Mental Health Research group. We made a screening research on women who had psychotherapy to monitor their condition, the screening was made with the help of "mental health quiz "Kyiv Mohyla Akademy" Psycho-social Rehabilitation Center"). The screener was received from the JHU Applied Mental Health Research Group and adapted for use in Ukraine by the employees of National University of "Kyiv Mohyla Akademy" Psycho-social Rehabilitation Center.

Results. According to our research, all women who have faced loss experienced different symptoms before therapy, for example:

\begin{tabular}{|l|r|}
\hline Symptoms & Percent \\
\hline Depression & $100 \%$ \\
\hline PTSD & $100 \%$ \\
\hline Anxiety & $45,80 \%$ \\
\hline Lowered interest in functioning & $91,70 \%$ \\
\hline Increased pressure & $70,80 \%$ \\
\hline Alcohol consumption & $25 \%$ \\
\hline
\end{tabular}

The following data is not representative of all women who have faced loss, women in our research are only those who came to get help themselves after they realized they cannot deal with the problem alone. Even though our research contains only a small part of women with the following problem it can be stated that this category of people needs a specialized, sometimes even complex help.

Due to our quiz, main complains are sleep disorder, fear of financial incapability, frightening memories, negative thoughts, panic attacks, bad mood, crying, nervous tremor, anger, suicidal thoughts, anxiety, lack of energy, fear of death, loss of life sense.

Dr. Yalom states that the process of overcoming loss has gender features: "a husband and a wife grieves differently, they cannot understand and support each other; one's grief 
disturbs other one's grief, makes disagreements and cools down the feelings between them. Many women feel the need to come back to their loss, they do it and want reconciliation. Many of them try to work on their projects again, want to bring back everything they had before, they seek for something that can bring meaning into their life.

Men need to be taught how to feel and share their grief, instead of hiding or choking it inside them.

O.Chaban and B.Bezsheiko confirm in their research "War zone stress" that overcoming loss has gender peculiarities in conditions of modern Ukraine.

The results of this research have shown that the same percentage of both men and women who have been in war zone areas have PTSD symptoms, meaning $20.9 \%$ and $20.0 \%$, women had a higher point on each symptom.

Our experience that was gained in three years of studies shows that that the problem of loss disturbs social connections of a patient, sometimes even breaks their social life. While observing the process of secondary socialization after loss we can state that it has two stages.

The first stage is desocialization, it is the opposite to socialization, this part of the process is based on the fact that women need to change their social role, from wife to widow.

Desocialization happens to numerous reasons:

1. Shock with the deprivation in all life spheres.

2. Devaluation of previous socialization experience.

3. Sharp change of social conditions.

4. Loss of the previous identity as mother, daughter, wife, etc.

5. Loss of previous opportunities.

Women have to reject their previous gender-role model as mother, wife, housewife, employee, her habits and skills to make a transition to a new stage because those usual roles become impossible or divergent in a new status.

We have often observed total or almost total social isolation, minimization of action that only maintains life in family or work system on the smallest level.

Many patients give up on their social interactions and opportunities, their faith, ideology, life values change completely. They experience a full range of reactions from devaluation of their personality, their life and life of their closest people to devaluation of life in general, micro and macro-social environment of a widow or a mother who lost her child.

Psycho-emotional condition of women experiences many changes, they avoid joy and feel constant pressure, they try to come back to grief again but in a new symbolic status.

Based on our data, desocialization has different stages and duration.

- Superficial short duration 1-6 month. The structure of the personality and life values remain the same.

- Deep- 7-23 month, the personality is ready for full change of their life values, social structure and relationship with other people and the environment.

- Pathological- more than 2 years. A person is stuck in the desocialization phase. Total estrangement, loss of moral guidelines. This stage requires special, professional help.

Among those who had individual therapy, almost every person who has overcome loss mentions that external factors have been the main impulse for recovery.

The next stage is resocialization. The moment, when women come back to their usual life but in new circumstances, resocialization happens. It can be either under social pressure or because of inner desire.

Factors that promote resocialization:

- Search of life sense, revaluation of inner priorities, self-concept change. 
- Realization of one's life-tasks.

- Social and family support. Renewing old social contacts or making new ones.

- Government's support for resocialization and financial support.

- Self-regulation skills.

- Healthy relationship with a dead one in the past.

Our experience based on individual and group psychotherapy shows that resocialization starts under pressure, women have to come back to their work and duties because of needs.

Social stigmatization of widows and mothers who lost their children on war leads to creating new social communities where women have support and comfort, where they feel unity. Furthermore, women enter a different stage of socialization, many of them change the social environment or job, life position and some aspects of their personality.

Resocialization also has different forms:

- $\quad$ Superficial- when a person stays in the same place in life but changes some strategies of behavior, for example, a widow who does not change her job but in addition has to do things that were usually done by her lost husband. She does not change her life position completely but still tries to support her life and life of her children on the same level.

- Deep- when a person changes their life completely, brings new social connections into it, creates new projects, changes a job or continues to work it the same place but considers new approaches. These changes are the manifestation of a new lifestyle, they show the unwillingness to follow old rules and norms.

- Unstable - when a person can't find a new sense for a long time and goes from desocialization to resocialization on and on when they can't form a new self-concept.

When the process of resocialization is in its starting position, supporting communities are very helpful, they provide psychological, physical and financial support. Widows and mothers who lost their children are looking for different resources that can be helpful for the family of a victim, they look for clothes and shoes for children, find doctors and psychotherapists, potential low-priced vacations.

Unfortunately, after some time these communities slow down the process of resocialization when members of the community start to compete with each other or compare themselves to others. It can drag resocialization down or bring a woman back to desocialization, which usually happens to a superficial form of resocialization.

The following situation is provoked by social stereotypes about women being slavish and incapable of autonomic living which puts this gender in the victim position.

After four years of war in Ukraine we can observe a huge variety of resocialization scenarios: getting married again, creating new business projects, changing a job, starting a volunteering or charity program, over concentrating on children, grandchildren, relatives, implementation of art projects, etc.

This way we consider desocialization and resocialization as parts of the socialization process, to be specific "secondary socialization". It occurs after a serious loss of someone close and requires a significant overview of old social habits and functions. Society plays an important role in secondary socialization process: nation, family, and environment.

To promote the process of secondary resocialization we suggest:

1. On the government level

- To refine the government politic about supporting families who lost their closest people.

- Social advertisement that honors the lives of the dead. Advertise that sets a healthy relationship with the family who lost their beloved people, not stigmatizing one. 
- Adding a ritual of honoring lives of the fallen to national celebrations and important dates.

- Creating the virtual memory book of the dead by the Ministry of Defence.

2. On the mass level.

- Rituals of honoring the memory of the dead and their families.

- Non-formal support. Creating support groups that can help to compensate lost opportunities or to fight social isolation, etc. also different kinds of support on the micro-social level can be helpful.

- Formation of specific moral and ethical principles that can help to build a healthier and stronger relationship with those families who lost one of their closest people.

- Social flash-mobs like "join mom of your lost friend for a tea", "be a Santa Claus for your dead friend's children", "share the warmth of your heart", "teach a son of your dead friend how to play football".

3.On the professional level.

- All widows and parents of the dead ATO members need to have a right for professional, prolonged, free of charge help in psycho-social rehabilitation centers.

- For those specialists who work with the mentioned type of clients have been created specific supervising systems that prevent emotional burnout.

- Special analytical and monitoring systems created in order to know the effectiveness of the treatment.

- Methodical and educational centers for training crisis psychologists.

Conclusions. This way we can conclude that the growth of military loss in the country makes it not only a personal problem but a national problem. Society has to be supportive and become a resource of help for those who lost their beloved ones. By giving a life of their family members away in order to help the nation those people have a full right to ask for the nation's support.

Society has to elaborate a moral imperative about the attitude towards dead ones and their families, people have to create a healthy environment to support the mental health of those who struggled the most at war. More specialists are needed to provide a professional help to the victims, those who will raise the psychological culture of the nation and help to overcome the problem of grief. The therapists need to have a positive experience with solving existential questions because it allows to stabilize the psychological condition of the patient as well as has a positive impact on the professional life of the therapist.

\section{References.}

Singh N.; Hopkins J.; Bogdanov S. Community Mental Health Intervention with WarAffected Persons in Ukraine//

URI: http://ekmair.ukma.edu.ua/handle/123456789/11947

Murray L.; Haroz E.; Doty S. B.; Singh N.; Bogdanov S.; Bass J.; Dorsey S.; Bolton P. Testing the effectiveness and implementation of a brief version of the Common Elements Treatment Approach (CETA) in Ukraine: a study protocol for a randomized controlled trial// URI: 
http://ekmair.ukma.edu.ua/handle/123456789/13866;

https://doi.org/10.1186/s13063-018-2752-y

Doty S. B.; Haroz E.; Singh N.; Bogdanov S.; Bass J.; Murray L.; Callaway K.; Bolton P. Adaptation and testing of an assessment for mental health and alcohol use problems among conflict-affected adults in Ukraine// URI: https://doi.org/10.1186/s13031018-0169-6

Murray L.; Haroz E.; Dorsey S.; Bolton P. (2014) A Common Elements Treatment Approach for Adult Mental Health Problems in Low- and Middle-Income Countries// Cognitive and Behavioral Practice N21(2):p.111-123, 2014. Reads https://www.researchgate.net/publication/261291940_A_Common_Elements_Tre atment_Approach_for_Adult_Mental_Health_Problems_in_Low-_and_MiddleIncome_Countries

Бойчук О.С., Костюк О.І. (2017) Феноменологія втрат: деякі психологічні особливості переживання вдовами та матерями, що втратили рідних в АТО / Новітні чинники впливу на формування особистості студента - майбутнього лікаря: Матеріали XVII міжн. наук.-практ. конференції, Київ, 2017 р. - К.: ПВНЗ КМУ УАНМ, 2017. - С. 29-30

Гошовський Я. (2008) Ресоціалізація депривованої особистості : монографія. Дрогобич : Коло, 2008. - 480 с. Десоциализация и ресоциализация//Кравченко А.И. (2001) Культурология: Учебное пособие для вузов.-М., 2001.

Лангмейер И., Матейчек 3. (1984) Психическая депривация в детском возрасте; пер. Г.А. Овсянникова. - Изд. 1-е русск.- Прага : ЧССР : Авиценум. Медицинское издательство, 1984. - 334 с

Keywords. military losses, mental effects, types of lesions, gender characteristics, means of assistance and re-socialization 


\title{
Towards a Recovery Orientated Mental Health Service: Findings from a National Consultation with Mental Health Service Users in Ireland
}

\author{
Pádraig Ó Féich \\ Mental Health Reform, National Coalition for Mental Health in Ireland, Dublin, Ireland
}

Background: In 2006, in a policy document entitled a Vision for Change (Department of Health, 2006), Ireland undertook to move towards a modern, recovery orientated public mental health service characterised by holistic care, individualised care planning, the provision of accessible support, increased involvement of service users in decisions about their treatment and care and greater continuity of care across the mental health services. More than a decade on, it remained unclear to what extent Irish mental health services had progressed towards the modern, recovery orientated system outlined in A Vision for Change (Department of Health, 2006).

Aim: Mental Health Reform's My Voice Matters project (Ó Féich et al., $2019 \mathrm{a} ; 2019 \mathrm{~b}$ ) aimed to address this by examining the views and experiences of mental health service users and the evidence for progress towards a recovery orientated public mental health service in Ireland. This project was the first large-scale national consultation in many years to provide detailed and up-to-date service user feedback.

Method: 1,188 participants who had accessed mental health services in Ireland in the last two years completed an in-depth online survey. The analysis was mainly descriptive in nature. However, an ordinal logistic regression was carried out to examine key factors associated with service user's overall experience of/satisfaction with the mental health service in Ireland.

Findings: Findings were mixed at best with a minority of participants experiencing services consistent with a recovery orientated approach as outlined in A Vision for Change (Department of Health, 2006). On average overall satisfaction was low with 42 percent of participants reporting a poor overall experience in the last two years. However, findings from the ordinal logistic regression indicated some ways in which service user experiences may be improved, which are consistent with modern, recovery orientated mental health care. Alongside age, the provision of individualised care plans, accessible support in the form of a key worker, service user involvement in decisions about their treatment and care, and continuity of care were found to be significant predictors of service user satisfaction. Calculated odds ratios showed, for example, that service users who reported having a written recovery/care plan and those who reported being involved in decisions about the medications they take were 2.2 and 2.5 times more likely to report a good overall experience, respectively.

Conclusion: More work is needed if Ireland is to achieve the modern, recovery orientated system envisaged in $A$ Vision for Change (Department of Health, 2006) more than a decade ago. However, key pillars of the recovery orientated approach, such as individualised care planning and increased service user involvement, have the potential to improve service user's 
experiences going forward.

\section{References}

Department of Health. (2006). A Vision for Change: Report of the Expert Group on Mental Health Policy. Dublin: The Stationery Office.

Ó Féich, P., Mitchell, K., Pérez, S. \& McDaid, S. (2019a). My Voice Matters: Report on a National Consultation with Mental Health Service Users. Dublin: Mental Health Reform.

Ó Féich, P., Mitchell, K., Pérez, S. \& McDaid, S. (2019b). My Voice Matters: Report on a National Consultation with Family, Friends and Carers/Supporters of Mental Health Service Users. Dublin: Mental Health Reform.

Keywords. Mental Health, Mental Health Service, Mental Health Service Users, Ireland. 


\title{
Impact of job burnout on mental health among social workers in public and private sector in Greece
}

Konstantinos Tsaras ${ }^{1}$, Evangelia Christopoulou ${ }^{2}$, Maria Malliarou ${ }^{1}$, Evangelos C. Fradelos ${ }^{3}$, Stiliani Kotrotsiou ${ }^{1}$, Ioanna V. Papathanasiou ${ }^{1}$.

${ }^{1}$ General Department, University of Thessaly, Larisa, GREECE.

${ }^{2}$ Direction of Social Welfare, Municipality of Thessaly, Larisa, GREECE.

${ }^{3}$ Psychiatric Department, Athens General Hospital for Thoracic Diseases "Sotiria", Athens, GREECE

\begin{abstract}
.
Purpose: This study examines the impact of job burnout on the social workers' mental health in public and private sector.

Material and Method: A descriptive, cross-sectional study was conducted in which 103 social workers who were working in public $(n=56)$ and private $(n=47)$ sector of the Thessaly region in Greece. Data were collected with a questionnaire including socio-demographic and work-related characteristics, the Maslach Burnout Inventory - Human Services Survey (MBI-HSS) and the General Health Questionnaire (GHQ-28). Independent t-test, anova and Pearson coefficient were used in statistical analysis.
\end{abstract}

Results: Emotional exhaustion was positively related to somatic symptoms $(\mathrm{r}=0.470, \mathrm{p}<0.001)$, anxiety/insomnia $(\mathrm{r}=0.429, \mathrm{p}<0.001)$, social dysfunction $(\mathrm{r}=0.365, \mathrm{p}<0.001)$, depression $(\mathrm{r}=0.252, \mathrm{p}=0.010)$ and overall mental burden $(\mathrm{r}=0.518, \mathrm{p}<0.001)$ of social workers. Personal achievements were negatively related to somatic symptoms $(r=-0.326, p=0.001)$, anxiety/insomnia $(r=-0.266$, $\mathrm{p}=0.007)$, social dysfunction $(\mathrm{r}=-0.321, \mathrm{p}=0.001)$, depression $(\mathrm{r}=-0.444, \mathrm{p}<0.001)$ and overall mental burden $(\mathrm{r}=-0.444, \mathrm{p}<0.001)$. Also, depersonalization was positively associated with somatic symptoms $(\mathrm{r}=0.218, \mathrm{p}=0.027)$, anxiety/insomnia $(\mathrm{r}=0.317, \mathrm{p}=0.001)$ and overall mental burden $(\mathrm{r}=0.258, \mathrm{p}=0.009)$.

Conclusion: All dimensions of burnout had a significant effect on mental health disorders of social workers in labor.

Keywords: Burnout, satisfaction, mental health, depression, stress, social workers 